\title{
The Use of Transmission Ultrasonics to Assess Bone Status in the Human Newborn
}

\author{
LINDA L. WRIGHT, MICHAEL J. GLADE, ${ }^{1}$ AND JAY GOPAL ${ }^{2}$ \\ University of Maryland School of Medicine, Department of Pediatrics, Baltimore [L.L.W., J.G.J. University of \\ Maryland, College Park, Maryland [M.J.G.]
}

\begin{abstract}
The applicability of transmission ultrasonics as a method for assessment of bone status in human newborns was investigated in two studies. Sound transmission velocity ( $\mathrm{SCV}$ ) through the intact distal radius and ulna was compared to midshaft bone mineral content (BMC) and to midshaft mechanical breaking strength (MBS) in 13 postmortem newborns [gestational age (GA) $=20$ to $41 \mathrm{wk}$. Midshaft MBS, ranged from 1 to $16 \mathrm{~kg}$; BMC, which ranged from 84 to $88 \mathrm{mg} / \mathrm{cm}$ in the term infant, was consistent with previous reported photon absorptiometric data. $\mathrm{SCV}$ in the distal radius and ulna was correlated with midshaft MBS $(r=0.69$ to 0.82$)$ and BMC $(r=0.85$ to 0.93$)$ and increased exponentially with midshaft MBS and BMC. GA was correlated with SCV ( $r=$ 0.90 to 0.95$)$. Log $\mathrm{GA}$ was correlated with midshaft MBS $(r=0.87$ to 0.96$)$ and BMC $(0.97$ to 0.99$)$ in each of the four measured bones. In the second study, SCV through the distal radius and ulna was measured in 85 live newborns ranging in GA from 28 to 43 wk. SCV increased linearly with GA ( $r=0.71$ to 0.77$)$. These data demonstrate that SCV through the distal radius and ulna increases linearly with GA and that SCV through the distal bones of the forearm is reliably related to midshaft $B M C$ and $M B S$ during the third trimester of gestation. Transmission ultrasonic measurement of SCV provides a rapid, reproducible, nonionizing, and noninvasive method for assessing bone strength and mineralization in human neonates. (Pediatr Res 22: 541-544, 1987)
\end{abstract}

\section{Abbreviations}

BMC, bone mineral content

GA, gestational age

MBS, mechanical breaking strength

$\mathrm{SCV}$, sound conduction velocity

SAS, statistical analysis system

The precise and accurate quantitation of bone mineralization in the human newborn and infant has been a methodologic challenge. Adaptation of the single-photon absorptiometric technique to neonates $(1-3)$ has allowed the longitudinal assessment of small bones of low mineral content. In this technique, a beam of radiation passes through the forearm and is detected by a

Received November 6, 1986; accepted June 24, 1987

Correspondence and reprint requests to Linda L Wright, M.D.. Department of Pediatrics, Rm S5A22, University of Maryland Hospital, 22 S Greene Street, Baltimore, MD 21201.

' Present address: Northwestern University, School of Medicine, Department of Pharmacology, Chicago, IL.

${ }^{2}$ Present address: Union Memorial Hospital, Department of Pediatrics, Baltimore, MD. scintillation detector. Changes in the beam intensity are proportional to the amount of mineral in a $1-\mathrm{cm}$ thick slice of bone. The radiation dose associated with each set of duplicate measurements of bone mineral and width is comparable to the radiation dose received during a pediatric chest radiograph (3), which limits the safety of photon absorptiometry for longitudinal studies. The safety of the method is also limited by the need to transport the infant to the study area and to mechanically restrain the limb (3), which restricts application of the technique to relatively healthy, nonfragile infants.

Interpretation of absorptiometric data from growing human newborns is also problematic. Photon absorptiometric estimates of midradial mineral content are linearly related to GA during the last trimester $(1-3)$; however, the relationship of these estimates to the mechanical strength and functional status of the forearm has not been demonstrated (3-5). A recent study of normal growing term infants by Hillman et al. (6) suggested that BMC photon absorptiometry may not be a useful measure of bone strength during postnatal growth and remodeling: during months 6 to $12 \mathrm{BMC}$ plateaued while bone diameter continued to increase. The authors suggested that this reflects a "hollowing out" phenomenon for increased mechanical advantage rather than demineralization.

An alternative method for the determination of bone strength is based on the sound conduction properties of bone. The velocity of an ultrasonic wave transmitted through bone reflects both elasticity and density (7), thereby providing a method for the assessment of mechanical strength that is sensitive to both growth and remodeling. The transmission of a sound wave through a limb is painless, noninvasive, insensible, and radiation free.

Although transmission ultrasonics has not been previously applied in human pediatric medicine, the accuracy of estimates of bone strength obtained from measurements of SCV has been validated in animals (8-12) and the diagnostic application of transmission ultrasonics is becoming increasingly routine in veterinary medicine $(9,11)$. Data collected from young horses and pigs indicates that the methodology provides a useful measure of bone strength in growing bone.

The purposes of this study were 1) to assess the relationship between SCV, MBS, and BMC in the human newborn (necropsy) during the last trimester of gestation; 2) to identify an accessible and reproducible site for the measurement of bone SCV in premature and term living newborns; and 3) to estimate the normal range of SCV at such a site.

\section{MATERIALS AND METHODS}

Study 1. Newborn autopsy material was obtained from the State of Maryland Anatomy Board on 13 infants that died within $14 \mathrm{~h}$ of birth. GA was determined from the date of the mother's last menstrual period and ranged from 20 to $41 \mathrm{wk}$. Both intact upper limbs were promptly frozen at $-20^{\circ} \mathrm{C}$ until $\mathrm{SCV}, \mathrm{BMC}$, and MBS were determined on the bones of the forearm. 
Immediately following thawing, SCV was measured in duplicate in the left and right limbs at the distal radius and ulnar stylus. The time required for the transmission of a standardized pulse of sound to travel through each location was measured on an Apple II-plus microprocessor (Apple Computer, Inc., Cupertino, CA) that had been modified so that it could be programmed to function as a digital oscilloscope with image storage and analysis capabilities (software and hardware provided by Equine Biomechanics, Inc., Unionville, PA). Signals of 400 nsecs' duration were generated (Pulser Receiver 5055PR, Panametrics, Waltham, MA) at a rate of $5 / \mathrm{s}$ for $4 \mathrm{~s}$ and were transmitted and received by $1-\mathrm{cm}$ diameter $2.25 \mathrm{mHz}$ disc contact transducers (Panametrics, Waltham, MA) mounted on an electronic steel microcaliper. The received signals were superimposed on the transmitted waveform, the signal-to-noise ratios were maximized by the microprocessor, and the resultant complex waveforms were averaged. The result was displayed on a video monitor (Amdek Corp., Arlington Heights, IL). The average elapsed time between the transmission and reception of a signal (transmission time $=t$ ) was measured on the screen within an accuracy of 0.09 $\mu \mathrm{s}$. The diameter of each specimen (transmission distance $=\mathrm{d}$ ) was measured simultaneously by the electronic caliper upon which the transducers were mounted. The velocity (SCV) of the sound pulses through the specimen was calculated $(S C V=d / t)$ and expressed in $\mathrm{m} / \mathrm{s}$.

The radius and ulna were then removed from each limb, dissected free of soft tissue, and placed in an apparatus to measure mechanical breaking strength directly (model 1132, Instron Co., Canton, MA). Breaking strength was determined by progressively loading the midshaft of a bone with increasing weight (3-point loading) and measuring the load necessary to induce rapid failure (fracture).

A 2-cm section, marked off before the bone was broken and including the fracture site, was then taken from each bone, placed into a preweighed porcelain crucible, and ashed at $900^{\circ} \mathrm{C}$ for 48 h. The crucible was cooled to room temperature under dessication and reweighed; BMC was determined by difference and expressed as $\mathrm{mg} / \mathrm{cm}$.

Pearson correlations between SCV, MBS, BMC, and GA were calculated using regression analyses with the SAS computer package.

Study 2. SCV was measured through the left and right distal radii and ulnas of 16 preterm and 69 term appropriate for gestational age infants in the Newborn Nursery and Neonatal Intensive Care Unit at the University of Maryland Hospital. The term infants were studied within the first 3 days of life; premature infants ( $\leq 37$ wk GA) were studied within the first 14 days of life. GA ranged from 28 to $43 \mathrm{wk}$ and was determined by initial physical examination upon admission to the nursery and confirmed at the time of study using the Ballard scale (13). Prior informed consent was obtained from the mother.

The study was conducted at bedside, often in the presence of the parents. The infants remained in their cribs as an assistant gently held the arm being examined in a neutral position (complete immobility is not required). Ultrasound jelly (Vaseline, Greenwich, CT) was applied to both sides of the wrist and duplicate measurements were obtained with removal and replacement of the calipers between measurements. Placement of the transducers was guided by the infant's bony landmarks; as a study 1 , the transducer heads were placed over the ulnar stylus and at the second ventral skinfold over the head of the radius. Replacement of the transducers for duplicate studies was aided by the slight impression in the skin made by the pressure of the transducers. Caliper contact time with the infants was approximately $60 \mathrm{~s}$ per reading.

\section{RESULTS}

Study 1 . Table 1 lists data for the autopsy specimens from 13 subjects; the range of values and the reliability of SCV, MBS, $\mathrm{BMC}$ are presented below. SCV measured through the intact thawed forearms ranged from 1345 to $1591 \mathrm{~m} / \mathrm{s}$. The correlation between $\mathrm{SCV}$ at the right and left corresponding distal radius and ulna was $r>0.95, p<0.001)$. Within each limb, distal radial and ulnar SCV were also highly correlated $(r>0.90, p<$ 0.001 ). The midshaft MBS of the cleaned, thawed radius and ulna ranged from 1.0 to $16.0 \mathrm{~kg}$. Midshaft MBS of the radius was highly correlated with that of the ipsilateral ulna $(r>0.93$, $p<0.001)$ and contralateral radius $(r>0.85, p<0.001)$.

Table 1. Characteristics of newborn bones at autopsy

\begin{tabular}{|c|c|c|c|c|c|c|c|c|c|}
\hline \multirow[b]{2}{*}{ Subject } & \multirow[b]{2}{*}{ GA } & \multicolumn{4}{|c|}{ Right } & \multicolumn{4}{|c|}{ Left } \\
\hline & & & $\mathrm{BMC}$ & MBS & SCV & & $\mathrm{BMC}$ & MBS & SCV \\
\hline \multirow[t]{2}{*}{13} & 20 & Radius & 15.0 & 1.35 & 1405 & Radius & 16.0 & 1.55 & 1345 \\
\hline & & Ulna & 16.1 & 1.45 & 1355 & Ulna & 15.6 & 1.55 & 1385 \\
\hline \multirow[t]{2}{*}{12} & 22 & Radius & 18.1 & 1.60 & 1420 & Radius & 16.1 & 2.00 & 1365 \\
\hline & & Ulna & 18.6 & 1.50 & 1368 & Ulna & 17.1 & 1.00 & 1410 \\
\hline \multirow[t]{2}{*}{17} & 23 & Radius & 19.9 & 3.50 & 1425 & Radius & 17.9 & 2.60 & 1375 \\
\hline & & Ulna & 20.2 & 2.05 & 1378 & Ulna & 20.3 & 3.25 & 1430 \\
\hline \multirow[t]{2}{*}{10} & 24 & Radius & 21.8 & 3.20 & 1430 & Radius & 24.8 & 3.50 & 1395 \\
\hline & & Ulna & 21.3 & 3.00 & 1398 & Ulna & 22.3 & 2.50 & 1430 \\
\hline \multirow[t]{2}{*}{7} & 25 & Radius & 24.0 & 3.40 & 1450 & Radius & 22.0 & 2.00 & 1450 \\
\hline & & Ulna & 24.3 & 1.90 & 1398 & Ulna & 24.4 & 2.60 & 1450 \\
\hline \multirow[t]{2}{*}{2} & 26 & Radius & 26.3 & 3.40 & 1470 & Radius & 29.3 & 3.05 & 1450 \\
\hline & & Ulna & 27.1 & 3.85 & 1418 & Ulna & 28.2 & 2.80 & 1455 \\
\hline \multirow[t]{2}{*}{11} & 27 & Radius & 28.8 & 4.80 & 1470 & Radius & 29.8 & 1.05 & 1480 \\
\hline & & Ulna & 28.6 & 4.30 & 1418 & Ulna & 28.9 & 2.35 & 1460 \\
\hline \multirow[t]{2}{*}{16} & 29 & Radius & 34.4 & 3.55 & 1527 & Radius & 32.4 & 2.20 & 1462 \\
\hline & & Ulna & 28.3 & 2.50 & 1438 & Ulna & 30.8 & 9.20 & 1436 \\
\hline \multirow[t]{2}{*}{5} & 32 & Radius & 39.5 & 5.25 & 1504 & Radius & 44.5 & 5.40 & 1534 \\
\hline & & Ulna & 40.6 & 5.80 & 1508 & Ulna & 45.8 & 8.76 & 1523 \\
\hline \multirow[t]{2}{*}{14} & 35 & Radius & 56.1 & 6.90 & 1519 & Radius & 50.1 & 6.40 & 1570 \\
\hline & & Ulna & 54.0 & 8.85 & 1502 & UIna & 61.9 & 11.90 & 1519 \\
\hline \multirow[t]{2}{*}{3} & 36 & Radius & 61.6 & 7.50 & 1537 & Radius & 53.6 & 8.60 & 1579 \\
\hline & & Ulna & 70.0 & 7.10 & 1591 & Ulna & 62.9 & 9.25 & 1582 \\
\hline \multirow[t]{2}{*}{15} & 40 & Radius & 83.7 & 8.50 & 1562 & Radius & 84.7 & 11.00 & 1561 \\
\hline & & Ulna & 87.4 & 9.50 & 1546 & Ulna & 87.9 & 6.80 & 1554 \\
\hline \multirow[t]{2}{*}{4} & 41 & Radius & 89.2 & 13.85 & 1510 & Radius & 93.2 & 16.00 & 1586 \\
\hline & & Ulna & 88.2 & 14.00 & 1541 & Ulna & 92.2 & 9.00 & 1534 \\
\hline
\end{tabular}


Midshaft radial and ulnar BMC at 40 wk was 84 to $88 \mathrm{mg} / \mathrm{cm}$ (range 15 to $93 \mathrm{mg} / \mathrm{cm}$ ). BMC of the midshaft radius and ulna was highly correlated with BMC of both the ipsilateral ulna and corresponding contralateral bone $(r=0.99, p<0.001)$.

The SCV of the distal radius and ulna was correlated with the midshaft MBS $(r=0.80$, range 0.69 to $0.82, p<0.001)$ and $\mathrm{BMC}(r=0.91$, range 0.85 to $0.93, p<0.001)$ in the corresponding bone (Figs. 1 and 2). SCV increased exponentially with MBS and BMC, predicted by the formulas MBS $=e^{(0.00095 C V-12.09)}$ (Fig. 1) and $\mathrm{BMC}=\mathrm{e}^{(0.008 \mathrm{~S}(\mathrm{CV}-7.59)}$ (Fig. 2). Midshaft MBS and BMC were linearly related: $\mathrm{MBS}=0.106 \mathrm{BMC}+0.839(r=0.96 ; p<$ 0.001 ).

The SCV, MBS, and BMC were correlated with GA in each of the four measured bones. SCV at the distal radius and ulna increased linearly with GA $(r=0.90$ to $0.95, p<0.001)$ (Fig. 3) and ranged from 1546 to $1562 \mathrm{~m} / \mathrm{s}$ at $40 \mathrm{wk}$. MBS of the radius and ulna increased with the log of GA $(r=0.87$ to $0.96, p<$ 0.001 ) (Fig. 4). BMC of the bones of the forearm were also correlated with the log of $\mathrm{GA}(r=0.97$ to $0.99 ; p<0.001)$ (Fig. 5).

Study 2. The mean birthweight and GA of the term infants were $3016 \pm 522 \mathrm{~g} \mathrm{(SD)}$ and $39.7 \pm 1.1 \mathrm{wk}$, respectively. The mean birth weight of the premature infants was $994 \pm 283 \mathrm{gm}$; their gestational ages ranged from 28 to $36 \mathrm{wk}$ (mean $30.4 \pm 1.8$ wk).

The range of SCV in the intact distal right radius in these minimally restrained newborns was 1387 to $1649 \mathrm{~m} / \mathrm{s}$. Duplicate measurements of SCV, conduction time, and limb diameter were highly consistent $(r=\geq 0.95)$; the mean coefficient of variation was $2 \%$. The correlation between left and right $\mathrm{SCV}$ in the intact

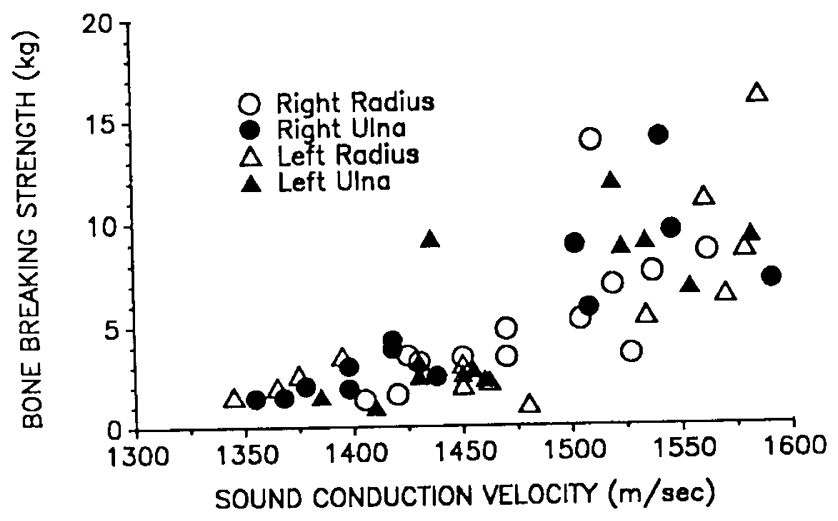

Fig. 1. Measured breaking strength of the cleaned midshaft radius and ulna versus sound conduction velocity through the distal corresponding neonatal bones; $n=13, r=0.80(p<0.001)$, MBS $=\mathrm{e}^{(0.00095 \mathrm{C} v-12.9)}$.

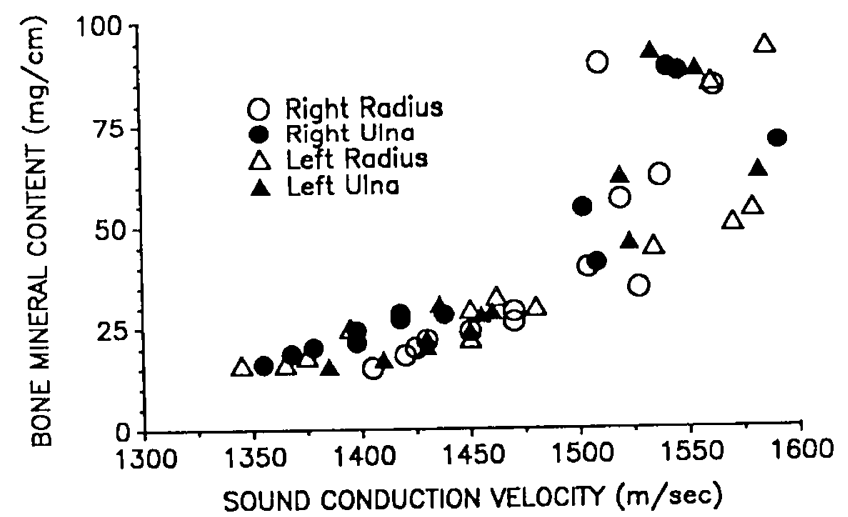

Fig. 2. Postmortem midshaft bone mineral content of the cleaned radius and ulna of newborns versus sound conduction velocity through the intact distal corresponding neonatal bones; $n=13, r=0.96(p<$ $0.001), \mathrm{BMC}=\mathrm{e}^{(0.008 \mathrm{SCV}-7.59)}$.

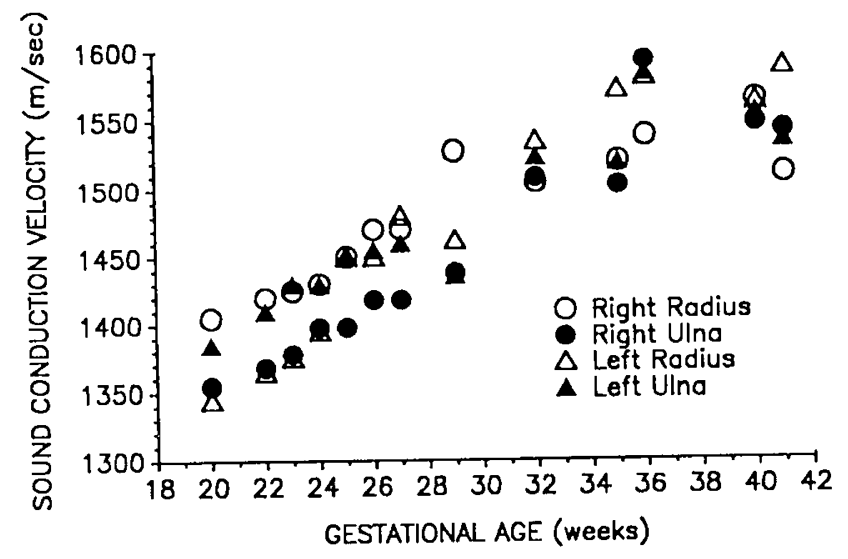

Fig. 3. Postmortem sound conduction velocity $(\mathrm{m} / \mathrm{s})$ through the intact distal radius and ulna of neonates versus gestational age; $n=13, r$ $=0.90$ to $0.95(p<0.001)$.

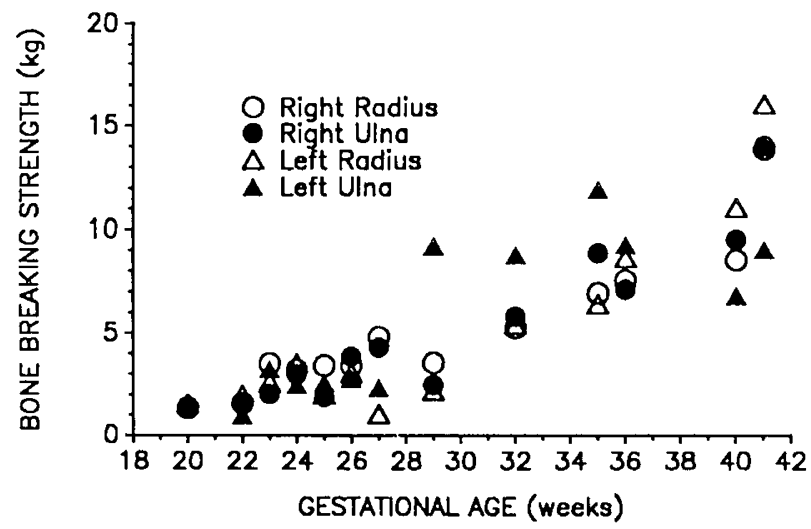

Fig. 4. Postmortem midshaft measured breaking strength of the cleaned radius and ulna of newborns versus the log of gestational age; $n$ $=13, r=0.87$ to $0.96(p<0.001)$.

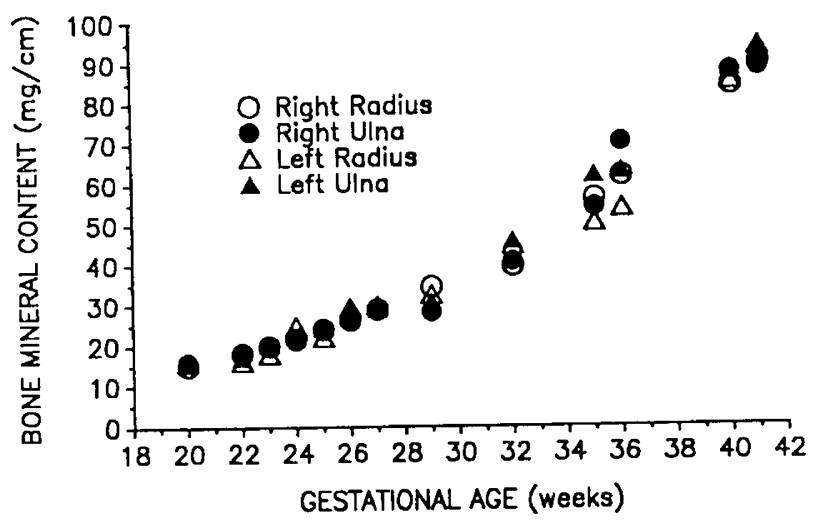

Fig. 5. Postmortem midshaft bone mineral content of the cleaned radius and ulna of newborns versus the log of gestational age; $n=13, r$ $=0.97$ to $0.99(p<0.001)$.

radius and ulna was $r \geq 0.74(p<0.001)$. Within each limb, SCV through the radius was significantly correlated with ulnar $\operatorname{SCV}(r=0.81, p<0.001)$.

SCV measurements through the intact distal right ulna of live, minimally restrained babies are illustrated in Figure 6 (similar data were obtained from the left radius and both ulnae). The pooled SE of an estimated sound velocity was $35 \mathrm{~m} / \mathrm{s}$. SCV was linearly correlated with GA between 28 and $43 \mathrm{wk}(r \geq 0.71, p$ $<0.001)$. SCV increased at a rate of 9.0 and $12.2 \mathrm{~m} / \mathrm{s} / \mathrm{wk}$ during wk 28 to 43. 


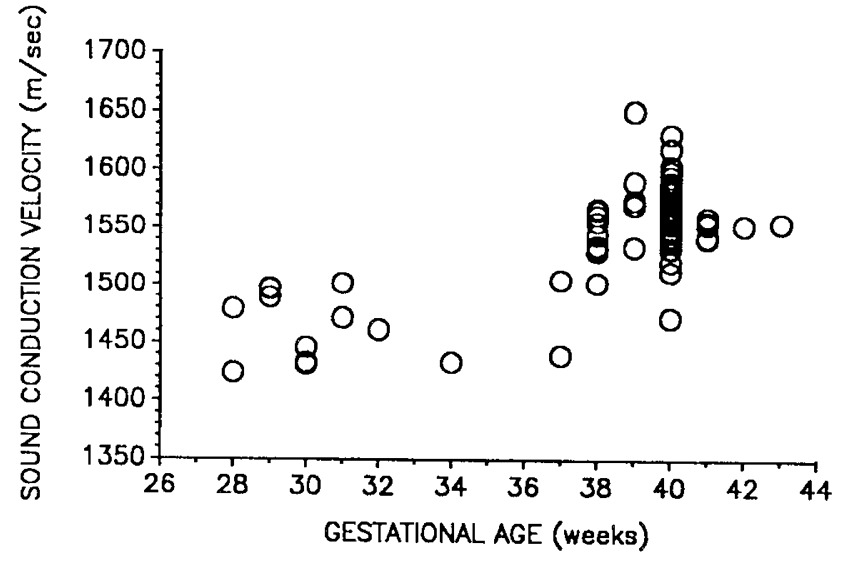

Fig. 6. Sound conduction velocity through the distal right ulna of living neonates versus gestational age; $n=82, r=0.77(p<0.001)$.

\section{DISCUSSION}

Bone is a composite of hard, crystalline mineral and a microfibrillar matrix into which the mineral is incorporated. Techniques that measure bone mineral density, such as ashing, radiographic photometry, and photon absorptiometry, estimate the density of mineral within the crystalline mineral matrix. An ideal method would reflect both mineral density and the elastic properties of the organic matrix, i.e. the microscopic architecture created by the mineral lattice, collagen orientation and organization, and vascular density. Transmission ultrasonics measures both elasticity and density: the velocity of a sonic wave (V) through a material is related to the modulus of elasticity of the material $(E)$ and its mass density $(p)$ by the equation $V^{2}=E / p$ (7). Previous research has demonstrated that the fastest sound conduction velocities in a limb are obtained through bone (10), allowing sound transmitted through it to be differentiated from slower signals conducted through the medulla and soft tissue.

Data from young animals suggest that transmission ultrasonics, unlike other methods, may provide a useful measure of bone strength in growing bones. There is a marked increase in the SCV of the lower leg bones of horses and pigs through the 1st yr of life $(10-12,14,15)$, the period of maximal postnatal equine and porcine limb growth. SCV and MBS increase linearly during this period, in both autopsy specimens $(11,12,14,15)$ and in living animals $(10,12)$ and are highly correlated in the intact lower extremities of live young horses $(r=0.91$, corrected for soft tissue) (12)

The data from this study indicate that transmission ultrasonics is a useful tool for the assessment of newborn skeletal status. $\mathrm{SCV}$ at the distal radius and ulna was significantly correlated with GA ( $r=0.90$ to 0.95$)$, as well as with midshaft $\mathrm{BMC}(r=$ 0.85 to 0.93$)$ and MBS $(r=0.69$ to 0.82$)$ in the corresponding bone. MBS and gravimetrically determined BMC were also highly correlated with the log of GA ( $r=0.87$ to 0.96 and 0.97 to 0.99 , respectively). These correlations compare favorably with that of BMC estimated via photon absorptiometry to GA $(r=$ 0.83 to 0.88$)(1,3)$. These results indicate that SCV in the distal bones of the forearm is reliably related to midshaft breaking strength and mineralization during rapid fetal growth of the third trimester. This conclusion was confirmed in living newborns varying in GA from 28 to 43 wk.

Previous photon densitometry research has been performed at the distal one-third of the radius $(1-3)$ or mid humerus $(4,16)$. The choice of sample site is regulated by numerous factors. Ideal bones for ultrasound interrogation are those with parallel borders that are surrounded by small amounts of soft tissue and reliably related to growth and disease status. The distal radius and ulna were chosen because of their accessibility, small amount of surrounding soft tissue, demonstrated vulnerability to rachitic changes, and natural landmarks.
The ease of clinical application of transmission ultrasonics compares favorably with photon densitometry. Measurements required approximately $1 \mathrm{~min}$ and necessitated neither removal of the infant from the bed nor complete immobilization of the limb. Reliability was excellent with a pooled standard error of $35 \mathrm{~m} / \mathrm{s}(2 \%)$ although, as with any instrumentation, some experience in using the equipment improved the consistency of the results.

In conclusion, our results suggest that the measurement of sound conduction velocity through bone provides a rapid, reproducible, nonionizing, noninvasive, and nontraumatic bedside method for the determination of bone strength and mineralization in newborns. Further studies will be required to define the optimal site for ultrasound interrogation, as well as the applicability of the technique to the quantification of longitudinal changes associated with postnatal growth and mineralization.

Acknowledgments. The authors thank Ron Wade of the Maryland Anatomy Board for providing bone specimens for the study; Paul Hellhake of Equine Biomechanics, Inc. and Tom Sherwin of Osteo Technology, Inc. for technical assistance; and Carole Villegas, Robbin Allison, and Margaret Kempf for preparation of the manuscript. We also thank Isabelita Frattarola and Susanne Ullsperger for their assistance in performing the readings and the Computer Science Center of the University of Maryland and the Statistical Analysis Group, ARS, USDA, Beltsville, MD.

\section{REFERENCES}

1. Minton SD, Steichen JJ, Tsang RC 1979 Bone mineral content in term and preterm appropriate-for-gestational-age infants. J Pediatr 95:1037-1042

2. Steichen JJ, Gratton TL, Tsang RC 1980 Osteopenia of prematurity: the cause and possible treatment. J Pediatr 96:528-534

3. Greer FR, Lane J, Weiner S, Mazess RB 1983 An accurate and reproducible absorptiometric technique for determining bone mineral content in newborn infants. Pediatr Res 17:259-262

4. Mazess RB, Peppler WW, Chesney RW, Lange TA, Lindgren V, Smith E, Jr. 1984 Does bone measurement on the radius indicate skeletal status? J Nuclear Med 25:281-288

5. Wilson CR 1974 Prediction of femoral neck and spine bone mineral content from the $\mathrm{BMC}$ of the radius or ulna and the relationship between bone strength and BMC, In: Mazess RB (ed) International Conference on Bone Mineral Measurement. DHEW Publication 75-683, US Department of Health, Education and Welfare, Washington, DC, pp 51-59

6. Hillman LS, Salmons SJ, Weaver E, Erickson MM, Hansen JW, Chao WT 1986 Bone mineral content of the humerus during first year in term infants fed breast milk, standard formula, and soy formula. Pediatr Res 20:412(abstr)

7. Ashman RB, Mayer DC, Cowan SC, Van Buskirk WD 1983 Elastic properties of human and canine femora. Transactions of the 29th Annual Meeting of the Orthopedic Research Society, March 8-10, 1983, Anaheim, CA. ORS, Parkridge, IL, 8:127(abstr)

8. Pratt GW 1980 An in vivo method of ultrasonically evaluating bone strength. Proceedings of the 26th Annual Convention of the American Association of Equine Practitioners, December 3, 1980, Anaheim, CA. AAEP, Golden, CO, pp 295-301

9. Rabin DS, Rantanen NW, Seder JA, Miller P, Hellhake P 1983 The clinical use of bone strength assessments in the thoroughbred race horse. Proceedings of the 28th Annual Convention of the American Association of Equine Practitioners, December 4-8, 1983, Las Vegas, NY. AAEP, Golden, CO, pp 343-350

10. Jeffcott LB, McCartney RN 1985 Ultrasound as a tool for assessment of bone quality in the horse. Vet Rec 116:337-342

11. Lawrence LA, Ott EA 1985 The use of non-invasive techniques to predict bone mineral content and strength in the horse. Proceedings of the Ninth Equine Nutritional Physiology Symposium, East Lansing, MI, 9:110-116

12. Glade MJ, Luba NK, Schryver HF 1986 Effects of age and diet on the development of mechanical strength by the third metacarpal and metatarsal bones of young horses. J Anim Sci 63:1432-1444

13. Ballard JL, Novak KK, Driver M 1979 A simplified score for assessment of fetal maturation of newly born infants. J Pediatr 95:769-774

14. El Shorafa WM, Feaster JP, Ott EA 1979 Horse metacarpal bone: Age, ash content, cortical area and failure stress interrelationships. J Anim Sci 49:979982

15. Tutsch L, Glade MJ, Sager AO 1986 Long bone growth in the limbs of the miniature Hormel-Harford swine. In: Tumbleson ME (ed) Swine in Biomedical Research, vol 2. Plenum Press, NY, 2:849-858

16. Vyhmeister NR, Linkhart TA, Hay S, Baylink DJ, Ghosh B 1987 Measurement of bone mineral content in the term and preterm infant. AJDC 141:507510 